\title{
Re: Oelschlager BK, Yamamoto K, Woltman T, Pellegrini C. Vagotomy During Hiatal Hernia Repair: a Benign Esophageal Lengthening Procedure. J Gastrointest Surg. 2008;12(7):1155-62.
}

\author{
Brant Oelschlager • Kyle Yamamoto • Todd Woltman • \\ Carlos Pellegrini
}

Received: 16 September 2008 / Accepted: 24 September 2008 /Published online: 21 November 2008

(C) 2008 The Society for Surgery of the Alimentary Tract

\section{Response to Dr. Herbella}

We would like to thank Dr. Herbella for his response to our recent article published in this journal concerning the use of vagotomy as an esophageal lengthening procedure. ${ }^{1}$ In this letter, he describes his experience with vagotomy, vagectomy, and vagal dissection in cadavers. His findings provide further evidence for what we have observed: that vagotomy increases the length of the esophagus after mediastinal esophageal mobilization. This is a phenomenon well known to us and many surgeons who deal with complex upper gastrointestinal diseases who encounter a foreshortened esophagus. This finding has not been well described in the literature, which is why we felt compelled to report this benefit, as well as the potential detriment (or in the case of

B. Oelschlager $(\bowtie) \cdot \mathrm{K}$. Yamamoto $\cdot$ T. Woltman $\cdot$ C. Pellegrini University of Washington,

Seattle, WA, USA

e-mail: brant@u.washington.edu our findings the lack there of), of vagotomy. Therefore, Dr. Herbella's findings are an important confirmation of our study and addition to the literature.

We are intrigued by Dr. Herbella's finding that vagal dissection away from the esophagus (as done in a vagal sparing esophagectomy) provides as much length as vagotomy. These finding by Herbella should be reproduced in patients, especially those with short esophagi. Vagal dissection is clearly more difficult and he did not show a difference in the increased esophageal length. Therefore, we prefer the ease of a unilateral vagotomy in the rare cases of short esophagi and are comforted by the lack of negative consequences reported in our study. We appreciate the opportunity to comment.

\section{Reference}

1. Oelschlager BK, Yamamoto K, Woltman T, Pellegrini C. Vagotomy during hiatal hernia repair: a benign esophageal lengthening procedure. J Gastrointest Surg. 2008;12:1155-1162. doi:10.1007/ s11605-008-0520-0. 